\title{
Analisis Pendapatan Usaha Pembuatan Tempe Dengan Tahu di Kota Langsa
}

\author{
Silvia Anzitha* \\ Program Studi Agribisnis Fakultas Pertanian Universitas Samudra \\ *email : silviaanzitha@unsam.ac.id \\ Diterima: Juni 2019; Disetujui: September 2019; Dipublish: Oktober 2019
}

\begin{abstract}
Abstrak
Tujuan dari penelitian ini adalah untuk menganalisis perbedaan pendapatan usaha pembuatan tempe dengan tahu di Kota Langsa Penelitian ini dilakukan dengan Metode Survei (Survey Method) dan dilaksanakan di Kota Langsa. Objek penelitian ini adalah pengusaha tempe dan tahu, meliputi produksi, harga, biaya produksi, nilai produksi dan pendapatan. Populasi dalam penelitian ini adalah pengusaha tempe dan tahu yang berada di Kota Langsa yang berjumlah 21 usaha. Sampel diambil dengan teknik pengambilan sampling jenuh. Hasil penelitian menunjukkan rata-rata biaya produksi yang dikeluarkan pengusaha tempe adalah sebesar Rp. 19.927.897/bulan, sedangkan rata-rata biaya produksi yang dikeluarkan oleh pengusaha tahu dalam produksinya adalah sebesar Rp. 16.157.541/bulan. Rata-rata nilai produksi pengusaha tempe adalah sebesar Rp. 27.461.538/bulan, sedangkan rata-rata nilai produksi pengusaha tahu adalah sebesar Rp. 20.812.500/bulan. Rata-rata pendapatan bersih pengusaha pembuatan tempe untuk penggunaan bahan baku kedelai sebesar $1000 \mathrm{Kg}$ oleh pengusaha tempe adalah Rp. 3.956.930 dan pengusaha tahu adalah Rp. 2.998.866.
\end{abstract}

Kata Kunci: Pendapatan, Tempe, Tahu, Langsa

\begin{abstract}
The aim of this research to analyze income difference of tempe and tofu bussines in Langsa city. This research used survey method dan conducted in Langsa city. The object of this research were a tempe and tofu bussines, including a production, price, cost production, production value and income. The population of this research all the tempe and tofu business in Langsa city that have 21 bussinessman. Sample taken with quota sampling method. The result show that cost production average of tempe bussines was $\mathrm{Rp}$. 19.927.897/month, meanwhile cost production average of tofu bussines was Rp. 16.157.541/month. Average of production value tempe bussiness was a Rp. 27.461.538/month, meanwhile average of production value of tofu bussines was Rp. 20.812.500/bulan. Income average of tempe business which used $1000 \mathrm{Kg}$ soybean and then produced to tempe was Rp. 3.956.930/month and tofu business was Rp. 2.998.866/month.
\end{abstract}

keyword: Income, Tempe, Tofu, Langsa

\section{PENDAHULUAN}

Pengolahan hasil pertanian merupakan kegiatan yang tak kalah penting dibandingkan dengan usahatani dalam menyediakan bahan pangan. Pengolahan hasil pertanian merupakan komponen kedua dalam kegiatan agribisnis setelah komponen produksi pertanian. Pengolahan hasil pertanian dapat diartikan sebagai suatu kegiatan merubah bahan pangan sehingga menjadi beraneka ragam bentuk dan macamnya dengan tujuan meningkatkan nilai tambah dari produk pertanian serta memperpanjang daya simpan dari produk pertanian. Salah satu pengolahan hasil pertanian yang sangat populer adalah pengolahan 
kedelai menjadi tempe dan tahu. Tempe dan tahu merupakan makanan tradisional yang telah lama dikenal di Indonesia. Pembuatan tempe dan tahu merupakan industri rakyat sehingga hampir setiap orang dapat dikatakan mampu membuat tempe dan tahu sendiri.

Perbedaan yang paling jelas antara produksi tahu dan tempe adalah untuk memproduksi tempe diperlukan modal empat kali lebih besar dari biaya operasional produksi tahu. Hal ini dikarenakan tempe yang siap dipasarkan membutuhkan tahapan serta waktu yang lebih lama daripada tahapan dan waktu dalam produksi tahu. Tempe yang siap dipasarkan harus melewati tahapan perendaman, perebusan, perendaman lagi, serta peragian, yang semuanya membutuhkan waktu sekitar empat hari. Sehingga dalam satu hari harus ada kedelai yang sedang diolah dalam masing-masing tahapan. Sedangkan untuk produksi tahu, dari mulai pengolahan kedelai mentah hingga menjadi tahu yang siap dipasarkan hanya memerlukan waktu satu hari.

Pembuatan tempe dan tahu dari kedelai juga sangat populer diusahakan masyarakat, dari industri kecil hingga industri besar. Industri rumah tangga pun dapat memproduksi tempe dan tahu sendiri karena peralatan yang digunakan dalam pengolahan kedelai ini tidak sulit didapatkan dan biaya pengolahannya juga relatif terjangkau.
Dalam pemasarannya tempe dan tahu produksi rumah tangga juga telah memiliki pasar sendiri, hal ini disebabkan tempe dan tahu merupakan makanan yang populer di Indonesia, dan dapat diperoleh dengan mudah serta harganya terjangkau.

Kota Langsa merupakan daerah yang memiliki usaha rumah tangga pengolahan kedelai menjadi tempe dan tahu. Berdasarkan data BPS Kota Langsa Tahun 2016, industri makanan dan minuman yang terdaftar di Dinas Koperindag Kota Langsa yang bergerak dalam bidang pembuatan tempe dan tahu berjumlah 21 usaha. Secara persentase usaha pembuatan tempe dan tahu adalah 9,50\% dari jumlah 221 industri makanan dan minuman di Kota Langsa.

\section{METODOLOGI PENELITIAN}

Penelitian ini dilakukan di Kota Langsa ditentukan dengan metode purposive sampling (sengaja). Penentuan Kota Langsa didasarkan atas pertimbangan bahwa di Kota Langsa terdapat 21 usaha pembuatan tempe dan tahu yang berada di dua kecamatan yang dimana produksinya untuk mencukupi kebutuhan konsumsi masyarakat Kota Langsa.

Berdasarkan jumlah populasi pengusaha tempe dan tahu yaitu sebanyak 21 pengusaha dimana semuanya dijadikan sampel dengan menggunakan sampling quota dengan rincian sebagai berikut: 
Tabel 1. Populasi Industri Pengolahan Tempe dan Tahu di Kota Langsa

\begin{tabular}{llc}
\hline No & \multicolumn{1}{c}{ Jenis Usaha } & Populasi \\
\hline 1 & Pengolahan Tempe & 13 \\
2 & Pengolahan Tahu & 8 \\
\hline \multicolumn{2}{c}{ Jumlah } & 21 \\
\hline
\end{tabular}

Sumber: Dinas Perindustrian Kota Langsa

Metode analisis yang digunakan adalah metoda analisis deskriptif, yaitu analisis pendapatan yang dirumuskan sebagai berikut:

$\mathrm{Pd}=\mathrm{TR}-\mathrm{TC}$

$\mathrm{TR}=\mathrm{Y}$. Py

$\mathrm{TC}=\mathrm{FC}+\mathrm{VC}$

Keterangan:

$\mathrm{Pd} \quad=$ Pendapatan $(\mathrm{Rp} /$ Bulan $)$

$\mathrm{TR}=$ Total Revenue (Rp/Bulan)

$\mathrm{TC}=$ Total Cost $(\mathrm{Rp} /$ Bulan $)$
$\mathrm{FC} \quad=$ Fixed Cost (Rp/Bulan)

$\mathrm{VC}=$ Variable Cost $(\mathrm{Rp} /$ Bulan $)$

$\mathrm{Y} \quad=$ Produksi (Kg/Bulan)

Py $\quad=$ Harga $(\mathrm{Rp} / \mathrm{Kg})$

\section{HASIL DAN PEMBAHASAN}

Berdasarkan hasil penelitian maka biaya yang dikeluarkan dalam usaha pembuatan tempe dan tahu di Kota Langsa adalah sebagai berikut:

Tabel 2. Pengeluaran Industri Pengolahan Tempe dan Tahu

\begin{tabular}{llrr}
\hline \multirow{2}{*}{ No } & \multirow{2}{*}{ Jenis Pengeluaran } & \multicolumn{2}{c}{$\begin{array}{c}\text { Pengeluaran Pabrik Pengolahan } \\
(\mathbf{R p} / \text { Bulan) }\end{array}$} \\
\cline { 3 - 4 } & & \multicolumn{1}{c}{ Tempe } & Tahu \\
\hline 1 & Penyusutan Peralatan & 112.994 & 70.431 \\
2 & Tenaga Kerja & 4.608 .173 & 3.662 .109 \\
3 & Sewa Tempat & 200.000 & 200.000 \\
4 & Bahan Baku & 15.006 .731 & 12.225 .000 \\
\hline \multicolumn{2}{c}{ Total Biaya } & 19.927 .897 & 16.157 .541 \\
\hline
\end{tabular}

Sumber: data primer

Berdasarkan tabel pengeluaran bahan baku pengolahan tempe dan tahu diatas, dapat diketahui bahwa biaya dalam pengolahan tempe lebih besar daripada pengolahan tahu. Pada biaya tenaga kerja, biaya pengolahan tempe lebih besar dikarenakan dalam pembuatan tempe pada tahap pembungkusan tempe membutuhkan tenaga kerja yang lebih banyak. Proses pembungkusan tempe membutuhkan waktu yang cukup lama dikarenakan membungkusnya dengan baik dan rapi serta dibungkus sesuai dengan ukuran tempe yang akan dibuat, sedangkan dalam pembuatan tahu tidak memerlukan proses tahapan yang membutuhkan tenaga kerja yang banyak. Tahu pada proses akhirnya hanya dicetak pada wadah yang telah disediakan kemudian dipotong sesuai dengan ukuran yang telah ada.

Disamping itu biaya bahan baku pada pengolahan tempe lebih besar dari 
pada tahu, disebabkan bahan baku yang diperlukan dalam pembuatan tempe lebih banyak daripada tahu. Adapun bahan baku yang digunakan dalam pembuatan tempe yaitu kacang kedelai, ragi, kayu bakar, daun pisang dan kertas koran, sedangkan dalam pembuatan tahu bahan baku yang digunakan yaitu kacang kedelai, cuka, plastik dan bahan bakar. Oleh karena itu biaya dalam pembuatan tempe membutuhkan biaya yang lebih besar. Adapun selisih biaya produksi pembuatan tempe dan tahu yaitu sebesar Rp. 3.770.357/bulan.

Dari biaya yang telah dikeluarkan maka nilai produksi yang dihasilkan dalam pengolahan tempe dan tahu yaitu sebagai berikut:

Tabel 3. Nilai Produksi dan Pendapatan Industri Pengolahan Tempe dan Tahu

\begin{tabular}{ccccc}
\hline No & Jenis Usaha & $\begin{array}{c}\text { Penerimaan } \\
\text { (Rp/Bulan) }\end{array}$ & $\begin{array}{c}\text { Total Biaya } \\
\text { (Rp/Bulan) }\end{array}$ & $\begin{array}{c}\text { Pendapatan } \\
\text { (Rp/Bulan) }\end{array}$ \\
\hline 1 & Tempe & 27.461 .538 & 19.927 .897 & 7.533 .641 \\
2 & Tahu & 20.812 .500 & 16.157 .541 & 4.654 .959 \\
\hline
\end{tabular}

Sumber: data primer

Berdasarkan tabel diatas diketahui bahwa nilai produksi pembuatan tempe sebesar Rp. 27.461.538,- dimana harga tempe yang dijual tergantung pada bentuk dan ukuran dari tempe tersebut. Adapun tempe yang berukuran lebar dan tipis dijual dengan harga $\mathrm{Rp}$. 200/bungkus, sedangkan yang berukuran kecil dan tebal dijual dengan harga Rp.250/bungkus. Dalam sehari rata-rata jumlah produksi tempe yang berukuran lebar dan tipis sebanyak 2.338 bungkus/hari, sedangkan tempe yang berukuran kecil dan tebal sebanyak 2.523 bungkus/hari.

Untuk pembuatan tahu nilai produksinya sebesar Rp.20.812.500,lebih kecil dari pembuatan tempe. Pengusaha tahu menjual tahunya dalam satuan per papan. Hal ini dilakukan karena dalam satu papan tersebut konsumen dapat meminta tahu dipotong dalam beberapa bagian. Umumnya dalam satu papan produksi tahu dibagi menjadi 60 sampai dengan 100 potong. Harga tahu per papan pada saat penelitian adalah Rp. 30.000/papan. Dalam sehari pengusaha tahu dapat menghasilkan rata-rata 27 papan tahu dengan harga jual sekitar Rp.30.000 - Rp. 32.000/papan.

Oleh karena itu besarnya pendapatan pengolahan tempe yaitu sebesar Rp. 7.533.641,- sedangkan pengolahan tahu sebesar Rp. 4.654.959,- , sehingga industri pengolahan tempe lebih untung dalam pendapatannya untuk pengolahan kedelai. Namun secara keseluruhan, kedua industri tersebut baik pengolahan tempe maupun pengolahan tahu secara perhitungan usaha menguntungkan sehingga untuk kedepannya akan pengusaha akan dapat mengembangkan usahanya untuk diusahakan. 


\section{SIMPULAN}

Rata-rata biaya produksi yang dikeluarkan dalam pembuatan tempe lebih besar dibandingkan pembuatan tahu disebabkan bahan baku yang dibutuhkan lebih banyak. Namun jumlah pendapatan yang diterima untuk industri pembuatan tempe lebih besar dari pada pembuatan tahu dengan selisih pendapatan sebesar Rp. 2.878.682, /bulan. Kedua industri tersebut berdasarkan perhitungan pendapatan merupakan industry yang layak diusahakan, oleh karena itu dibutuhkan peran pemerintah dalam penyediaan bahan baku kedelai dan menjaga kestabilan harganya.

\section{DAFTAR PUSTAKA}

Astawan, Made dan Wahyuni. 2001. Teknologi Pengolahan Pangan Tepat Guna. Akademi Pressindo. Jakarta.

Badan Pusat Statistik Kota Langsa. 2017. Kota Langsa dalam Angka 2016. Langsa.
Irwan A.W., 2006. Budidaya Tanaman Kedelai (Glycine max (L.) Merill). Fakultas Pertanian, Universitas Padjadjaran. Jatinangor.

Koswara, S. 2009. Teknologi Pengolahan Kedelai. Pustaka Sinar Harapan. Jakarta.

Musa, Mohammad. 2008. Metode Penelitian. Fajar Agung. Jakarta.

Partadireja. 2001. Perhitungan Pendapatan Nasional. Rajawali Press. Jakarta.

Singarimbun. Masri. 2006. Metode Penelitian Survei. Jakarta. LP3ES.

Sudjana. 2005. Buku Penelitian dan Penilaian. Sinar Baru: Bandung.

Sukirno, Sadono.2007. Makro Ekonomi. Raja Grafindo Persada. Jakarta.

Soekartawi. 2002. Analisis Usaha Tani. UIPress. Jakarta.

Sugiyono. 2009. Statistika untuk Penelitian. Alfabeta. Bandung.

Syarief. 2007. Wacana Tempe Indonesia. Universitas Katolik Widya Mandala. Surabaya.

Tarwotjo C. S. 2005. Dasar-dasar Gizi Kuliner. Grasindo. Jakarta.

Umar, Husein. 2008. Riset Pemasaran Dan Perilaku Konsumen. PT. Gramedia Pustaka Utama. Jakarta.

Winarno F.G. 2004. Kimia Pangan dan Gizi. Gramedia Pustaka Utama. Jakarta. 